\title{
Prospects of Extracellular Vesicles in Otorhinolaryngology, Head and Neck Surgery
}

\author{
Metka Sluga $^{1}\left(\mathbb{D}\right.$, Saba Battelino ${ }^{2,3}(\mathbb{D})$ and Domen Vozel ${ }^{2,3, *(\mathbb{D})}$ \\ 1 University Children's Hospital, University Medical Centre Ljubljana, SI-1000 Ljubljana, Slovenia; \\ metkasluga9@gmail.com \\ 2 Department of Otorhinolaryngology and Cervicofacial Surgery, University Medical Centre Ljubljana, \\ SI-1000 Ljubljana, Slovenia; saba.battelino@kclj.si \\ 3 Faculty of Medicine, University of Ljubljana, SI-1000 Ljubljana, Slovenia \\ * Correspondence: domen.vozel@kclj.si
}

check for updates

Citation: Sluga, M.; Battelino, S.; Vozel, D. Prospects of Extracellular Vesicles in Otorhinolaryngology, Head and Neck Surgery. $J$. Nanotheranostics 2021, 2, 208-223. https://doi.org/10.3390/jnt2040013

Academic Editor: Moein Moghimi

Received: 31 October 2021

Accepted: 23 November 2021

Published: 28 November 2021

Publisher's Note: MDPI stays neutral with regard to jurisdictional claims in published maps and institutional affiliations.

Copyright: (c) 2021 by the authors. Licensee MDPI, Basel, Switzerland. This article is an open access article distributed under the terms and conditions of the Creative Commons Attribution (CC BY) license (https:/ / creativecommons.org/licenses/by/ $4.0 /)$.

\begin{abstract}
The diagnostic and therapeutic potential of extracellular vesicles (EVs) has been recognised in many fields of medicine for several years. More recently, it has become a topic of increasing interest in otorhinolaryngology, head and neck surgery (ORL-HNS). With this narrative review, we have aspired to determine different aspects of those nanometrically sized theranostic particles, which seem to have promising potential as biomarkers in some of the most common diseases of the ORL-HNS by being available via less invasive diagnostic methods. At the same time, a better understanding of their activity provides us with new possibilities for developing specific target treatments. So far, most research has been oriented towards the role of EVs in the progression of head and neck cancer, notably head and neck squamous cell cancer. Nonetheless, some of this research has focused on chronic diseases of the ears, nose and paranasal sinuses. However, most research is still in the preclinical or experimental phase. It therefore requires a further and more profound understanding of EV content and behaviour to utilise their nanotheranostic capacities to their fullest potential.
\end{abstract}

Keywords: extracellular vesicles; exosomes; liquid biopsy; squamous-cell carcinoma; chronic rhinosinusitis; cholesteatoma; immunomodulation; drug delivery carriers

\section{Introduction}

With growing interest in the use of nanotechnologies in medicine, research on EVs has spread from various medical fields to otorhinolaryngology, as well as head and neck surgery (ORL-HNS). In the last three years, there has been a significant increase in the literature discussing their potential use in diagnostics and the treatment of diseases covered by ORL-HNS [1]. Much of the research has focused on the particular roles and content of EVs, which helps us to understand better the development and progression of diseases on a molecular level and, therefore, improve diagnostics and targeted therapy. On the other hand, some research has used a more general approach, reviewing the so-far known activity of these nano-sized particles and developing additional ideas for their use in the future.

We aimed to research general and already established bases of the use of EVs and to find more concrete examples, demonstrating the potential of EVs in specific cases. The first part of the review therefore focuses on the structure and physiology of EVs, followed by an explanation of methods used for their isolation from body fluids and a further specification of their characteristics. The second part briefly focuses on general principles of the use of EVs for diagnostic and therapeutic purposes, followed by a more detailed description of their use in ORL-HNS, supported by examples based on specified studies.

As dictated by the availability of new literature, most examples refer to cancerous diseases, since their burden probably stimulates the most interest for possible treatment options. In conclusion, we have summarised the latest discoveries, with an emphasis on 
the most apparently promising ones, bearing in mind that future research in this relatively new chapter in otorhinolaryngology still has many questions to answer.

\section{Background of EVs}

As defined by the International Society for Extracellular Vesicles (ISEV), EVs are particles naturally released from cells, delimited by a lipid bilayer, which cannot replicate since they do not contain a functional nucleus [2].

They should be described at least by their (1) physical characteristics based on their size (small < $200 \mathrm{~nm}$, medium/large > $200 \mathrm{~nm}$ ) and density (low, middle or high); (2) biochemical composition (e.g., Annexin A5-stained EVs) and (3) condition of origin (e.g., hypoxic EVs) or cells of origin (e.g., apoptotic bodies, podocyte EVs). If these three minimal requirements are not met, and the identification of the EV is not achieved, the EV should be termed an extracellular particle [2]. Recently, a new type of nano-sized extracellular particle, called an exosphere, has been discovered. However, a lipid bilayer does not delimit their exospheres; they are not therefore EVs [3].

In addition to these requirements, EVs should be characterised in detail based on more specific protein markers to determine the EV nature and the degree of purity of an EV preparation, so as to enable specific analysis of small EVs and to document functional activities of EVs [2].

Moreover, EVs can be classified according to the pathway of their biogenesis, if it is clearly assigned (e.g., documented with live imaging technique), to endosome-origin exosomes and plasma-derived ectosomes (microvesicles, microparticles, ectosomes, large oncosomes and apoptotic bodies) (Figure 1) [2,3].

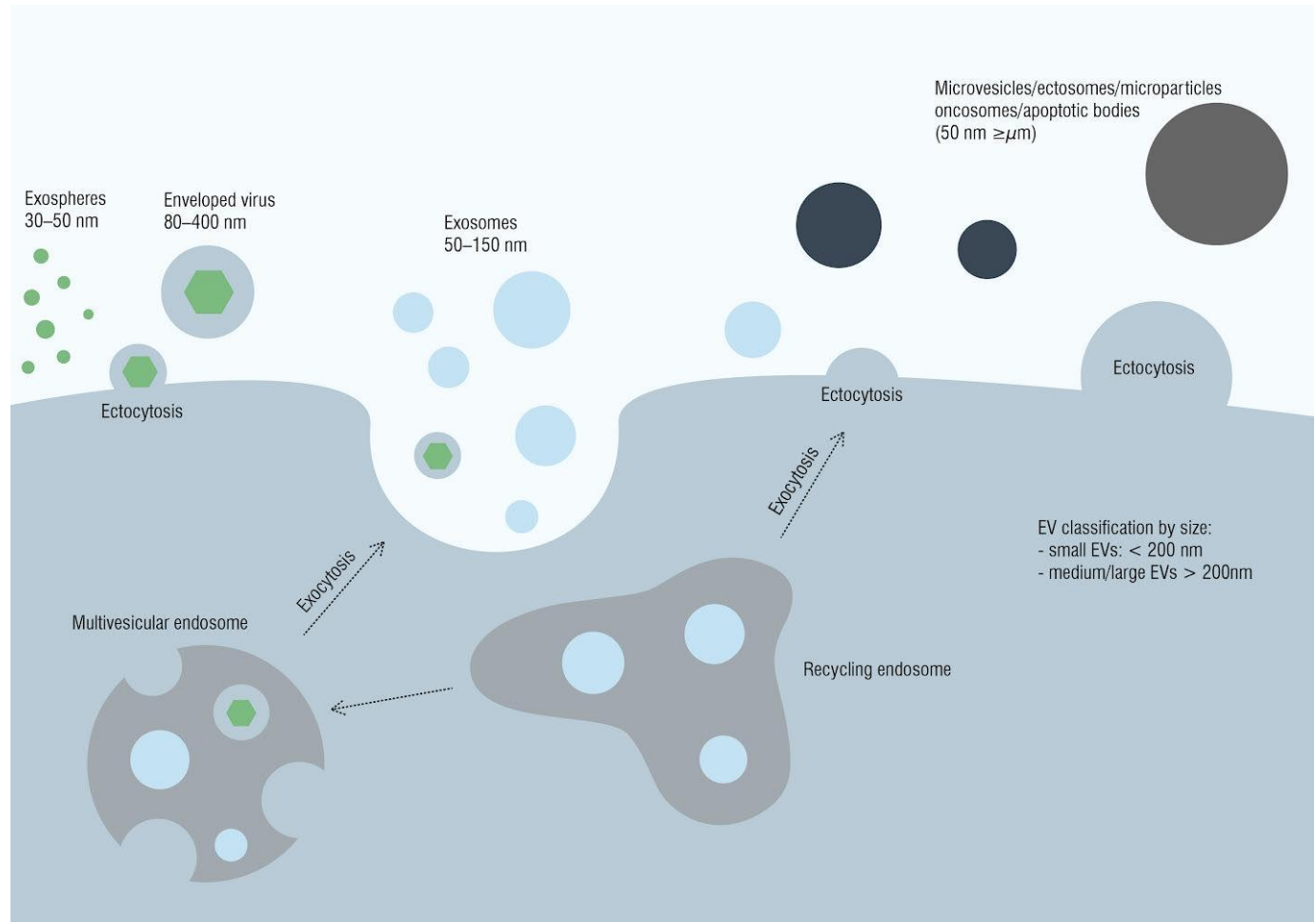

Figure 1. Subtypes of EVs. The scheme illustrates the classification of EVs according to their biogenesis pathway.

Despite the requirements mentioned above, there is still controversy ongoing with regard to EV nomenclature. Some authors use the term small EVs, but others prefer exosomes. The term exosome seems to be a somewhat more popular term among authors, and the term small EV is regularly replaced by this less accurate and exact expression, which is often used as a generic descriptor of EVs [4]. In this review, we stand by the term 
EV-however, when presenting the results of studies mentioned below, the term may have been replaced by whatever was initially used by the authors, which was mostly exosome.

\subsection{Formation of EVs}

Since most of the literature refers to exosomes, this section focuses on a description of exosomes. The initial step in forming exosomes is the aggregation of proteins and lipids (i.e., microdomain formation) on the membrane of large intracellular vesicles, generally of an endocytic origin. This results in twisting the vesicle membrane inward and the formation of intraluminal vesicles (ILVs). The resulting large vesicle with ILVs is called a multivesicular endosome (MVE). Some resulting ILVs are later excreted into the extracellular space as exosomes via the exocytosis of MVE, and some ILVs are degraded within the cell. At this stage, ILVs have been renamed exosomes [3-6].

\subsection{Cargo Composition of EVs}

In addition to proteins essential for EV biogenesis, transport and fusion, EVs can carry other proteins crucial for cell targeting and lipid metabolism, components of the extracellular matrix, cell surface receptors, cytoskeletal components, signalling molecules and metabolic enzymes. At the same time, their membrane is enriched with different types of lipids, which provide them with stability. Another essential aspect is EVs' ability to carry functional ribonucleic acids (RNAs), which may be of cellular origin, distinct, tissue-specific or universal among all exosomes. For instance, some exosomes released by tumours may contain single-stranded deoxyribonucleic acid (ssDNA), genomic DNA, circular DNA (cDNA) and other transposable elements (i.e., transposons, DNA sequences that may change their position within the genome, responsible for genetic mutations) $[7,8]$. However, the role of exosomal DNA (ExoDNA) is much less studied compared to RNA. It has been reported that ExoDNA plays a role in tumour immunity modulation and, being secreted out of cancer cells in exosomes, provides a relevant liquid biopsy material for the detection of important genetic mutations [9]. On the other hand, a recent reassessment of exosome content has shown that small EVs do not contain or actively release DNA, suggesting autophagy and MVE-dependent but exosome-independent mechanisms in the active secretion of extracellular DNA [10].

Evidence shows that EVs of different cellular origins often share highly expressed vesicular proteins (e.g., CD63, CD9 or CD81). On the other hand, they carry another less abundant protein component, which reflects their specific mother cell and varies among different EV subpopulations, and this also provides the basis for particular biomarker development. However, there is no typical single biomarker that can be identified on EVs only, so EV discrimination usually depends on their containing protein aggregates or viruses associated with EVs [11].

\subsection{Dynamics and Kinetics of EVs}

When released into the extracellular space, EVs can further exert effects on their target cell (i.e., mother, adjacent or distant cell) by two modes of action: (1) binding with a plasma membrane receptor, which induces intracellular signalling; or (2) fusing with the target cell membranes, which induces EV uptake [6,12]. Mulcahy et al. (2014) described EV uptake mechanisms, including clathrin-dependent endocytosis, caveolin-mediated endocytosis, phagocytosis, the interaction of EV with the lipid rafts, and macropinocytosis [11,12].

Once EVs enter the systemic circulation, they target distant tissues. Since exosomes cross the blood-brain barrier, they also exert essential roles in developing brain metastasis [13]. As a result, they are eliminated through the liver, lungs and kidneys, or may, at the same time, be inactivated by the immune system [11].

\subsubsection{Role of EVs in the Modulation of the Tumoral Microenvironment}

The role of EVs in intercellular communication, especially in cancer development, has been well studied. They play a crucial role in the modulation of the tumoral microen- 
vironment (TME). TME refers to the surroundings of the tumour cells, which encloses them and actively contributes to the tumour's development, progression, metastasis, and drug resistance. TME is composed of heterogeneous cellular components such as cancer-associated fibroblasts, myofibroblasts, adipocytes, endothelial and epithelial cells, immune cells, and the extracellular components surrounding them [14].

EVs from cancer cells activate receptors or change RNA expression in adjacent target cancer cells, promoting uncontrollable independent growth. This results in the independent growth of cancerous cells, the stimulation of their survival, tumour invasion and the evasion of immune surveillance [15]. Furthermore, EVs from cancer cells enable communication between cancer cells and between cancer and normal stromal cells. Since stromal cells accept cancer EVs, they promote the growth of the pro-tumoral microenvironment, and stromal cells release EVs to target cancer cells in reverse. The latter upregulates endothelial cell proliferation and angiogenesis in cancer tissue, leading to cancer growth and invasion [16]. The effects of EVs reach stromal cells in distant tissues, where they modify and create more favourable microenvironments (i.e., pre-metastatic niches) before the arrival of metastatic cells. These investigations imply a critical role of EVs in the process of metastasis $[15,17]$.

The potential of oral cancer-derived EVs to change the TME by initiating epithelial cell transformation and promoting the tumorigenic and invasive capabilities of oral cancer cells has been demonstrated with the siRNA (small interfering RNA)-mediated triple silencing of the CDC37/HSP90 $\alpha / \mathrm{HSP} 90 \beta$ complex, which substantially diminishes the pro-malignant activities of oral cancer cells as a result of the weakened EV transmission activity in cell-to-cell communication in the TME [18].

\subsubsection{Immuosuppressive Roles of EVs in Cancer Progression}

The progression of head and neck cancer (HNC), including oral squamous cell carcinoma, partially results from profound immunosuppression, often defined by low lymphocyte counts, altered T-cell and natural killer cell activity, disposition for T-cell apoptosis and impaired antigen-presenting function. Various mechanisms of tumour-induced immune suppression have been described [19].

Abundantly produced by tumorous cells, EVs, and more specifically tumour-derived exosomes, have recently risen as an essential factor in regulating anti-tumour immunity. Razzo et al. (2019) studied the effects of immunosuppressive exosomes carrying PDL1 (programmed death-ligand 1) and FasL (Fas ligand), isolated from supernatants of murine or human head and neck squamous cell carcinoma (HNSCC) cell lines. A single intravenous injection of tumour-derived exosome (TEX) into immunocompetent mice with premalignant oral/oesophageal lesions, induced by the carcinogen 4-nitroquinoline 1-oxide (4NQO), increased the number of developing tumours, and reduced the numbers of CD4+ and CD8+ T cells infiltrating the growing tumours [20].

Exosomes isolated from the serum of hypopharyngeal carcinoma patients have been proven to inhibit CD8+ T cell function, and at the same time increase the expression of PD-1 (programmed death-ligand 1) and PD-1/PD-L1 pathway activation, which plays an essential role in hypopharyngeal carcinoma immune escape and lowers the response of the immune system to cancer cells. This revelation presents a potential target of the immunosuppression of hypopharyngeal carcinoma, which would lead to improvements in tumour immunotherapy [21].

Another study investigated the role of exosomes in the interference with immune response in patients with different types of HNSCC after treatment. After treatment, exosomes isolated from the plasma of patients with active HNSCC seem to induce much stronger apoptosis of CD8+ T cells, the more significant inhibition of T-cell proliferation or NKG2D (activating receptor of the NKG2 family) expression on natural killer cells, and the better up-regulation of suppressor functions in CD4+CD39+ Treg (regulatory T cells), compared to patients with no evident disease. The suppression of immune response 
seems to correlate with disease activity and indicates the valuable role of exosomes as biomarkers in HNSCC progression [22].

\subsection{Protocols and Methods for EV Isolation}

EV harvest and isolation from extracellular fluids, either body fluids or a cell-cultured media, is one criterion that defines EVs. The collection of these fluids should be as gentle as possible, minimising cell disruption, which could cause the isolation of EVs from intracellular compartments, compromising the pureness of the isolated EVs [23].

However, there has not yet been a definite description of a standard protocol for EV harvest and isolation, since it depends on the body fluid or cell-cultured media used for the examination. In addition, EVs share a similar size and density within their subtypes and with some lipoproteins and viruses, which further complicates their size- or densitybased isolation [24].

Ultracentrifugation remains the gold standard and most popular method for EV isolation. The procedure consists of three centrifugation steps with increasing forces, which separate EVs from cells, sizeable cellular debris, organelles, microvesicles and, finally, the supernatant. However, the procedure is time-consuming and expensive, uses large amounts of untreated samples, and possibly damages the EVs [25].

Size-based techniques include different ultrafiltration methods that use nanomembranes with defined molecular weight cut-offs, and widely isolate EVs from more diluted samples [24]. The increasingly popular size exclusion chromatography distinguishes macromolecules based on their molecular size or hydrodynamic volumes. Flow field-flow fractionation distinguishes macromolecules based on their diffusion coefficients. These methods are usually less damaging to EVs, but are quite time-consuming and may not be as accurate since they cannot distinguish EVs from other similarly sized molecules [24-26].

The polymer precipitation method uses hydrophobic polymers to precipitate EVs through changing solubility and dispensability. It has been used to isolate viruses and macromolecules for many years, but has the downside of the co-precipitation of other proteins or lipoproteins [26].

Affinity-based techniques utilise selective interactions between proteins or receptors on the EV membrane and their corresponding ligands. The method usually consists of specific antibodies attached to a magnetic bead, which allow a binding reaction with particular surface proteins expressed by EVs. This method provides high-purity isolates, but is expensive and thus not suitable for isolating large amounts of EVs [24].

Charge-based techniques are classified as ion-exchange techniques, using the interactions between negatively charged EV membranes and positively charged anion exchangers and electrophoresis [24].

\subsection{Characterisation of EVs}

The characterisation of EVs is based on their physiochemical properties, for example, shape, size, surface charge or density. In 2020, the ISEV Rigor and Standardization Subcommittee performed a worldwide survey on methods to distinguish and characterise EVs. Most participants reported using Western blotting for the characterisation, with singleparticle tracking being a close second, followed by protein concentration and electron microscopy, flow cytometry, functional assay, mass spectrometry, and other less common characterisation methods [27]. When profiling the characteristics of EVs, most studies used a combination of the methods mentioned above.

The MISEV2014 guidelines define the recommended steps for EV characterisation. First, the source of EVs and EV preparation should be described quantitively, providing the number of cultured cells, and the volume of biofluid or tissue used, followed by global quantification of EVs, with the most common methods using total protein amount and total particle number. As of 2018, a more detailed table of EV proteins has been provided, with some categories presenting mandatory and some recommended sets of proteins that should be determined for the specification of EV subtypes, depending on the focus of the 
study. To characterise a single EV, techniques providing high-resolution images, the most common being electron microscopy and related techniques, scanning probe microscopy (SPM), atomic-force microscopy (AFM) and super-resolution microscopy, should be used. Other single-particle analysis techniques that measure the biophysical features of EVs may also be used, such as size measured by resistive pulse or light scattering properties, high-resolution flow cytometry, multi-angle light scattering coupled to asymmetric flow field-flow fractionation, or fluorescence analysis. In addition, assessment of the topology of EV-associated components, regarding whether the component is luminal or on the surface, is recommended [2].

\section{Applicability of EVs in ORL-HNS}

In recent years, studies of the role of EVs in disease progression, diagnostics, treatment, control of its efficacy and prognosis regarding ORL-HNS diseases have increased, offering new approaches for diagnostics and more specified therapy.

In the recent literature, the prevailing point of interest has been the role of EVs in HNC, most commonly exosomes in head and neck squamous cell cancer (HNSCC) [28]. A few other publications explore EVs' role in relation to chronic rhinosinusitis [29], nasal polyposis [30], sensory hair cell protection in the inner ear [31], traumatic hearing loss [32], middle ear cholesteatoma [33] and taste bud regeneration [34].

\subsection{EV-Based Diagnostics}

\subsubsection{Head and Neck Cancer}

HNSCC typically originates in deeper tissues and is usually harder to see or palpate. For that reason, it is often discovered too late, i.e., when it has already progressed locally or metastasised to the cervical lymph nodes. Approximately two-thirds of patients with HNSCC are diagnosed at an advanced stage, and more than half of them experience a recurrence at least once, $90 \%$ of them within the first two years [35]. This contributes to the high burden of HNSCC; prompt diagnosis is therefore crucial [29-34].

When it comes to diagnostics, some exosomal molecules' unique and consistent expression patterns make them a promising biomarker in some diseases of ORL-HNS. Since EVs are ubiquitous, they can be isolated from tumour liquid biopsy samples or non-invasively collected body fluids, e.g., saliva, plasma, urine. Although using EVs in these settings is becoming increasingly popular in diagnosis, their use is still limited due to the overlapping cellular structure and composition of the tumour and normal cells [36].

Recently, the most often studied potential EV-related biomarkers from different samples, including the above-mentioned diagnostic methods, have been EV levels, EV DNA, RNA and protein cargo, as summarised in Table 1.

A study by Hoshino et al. (2020) provided a proteomic analysis of EV and particles (EVPs) from 426 human samples, identifying pan-EVP markers, and biomarkers for EVP isolation, cancer detection and cancer type. In addition, a study of EVP proteomes was run to identify universal EVP markers, improve the isolation of human EVPs and offer a resource for early cancer detection with liquid biopsies. Among the exosome markers investigated, HSPA8 (Heat Shock Protein Family A (Hsp70) Member 8), HSP90AB1 (Heat Shock Protein 90 Alpha Family Class B Member 1), CD9, and ALIX (apoptosis-linked gene 2-interacting protein $\mathrm{X}$ ), isolated from cells, tissues, and most biofluids, were found to be the most prominent and represent the so-called pan-EVP markers [37].

Tumour tissue biopsies and fine-needle aspiration biopsies are the most commonly used diagnostic methods in ORL-HNS. However, due to their invasive nature and inadequate representation of tumoral heterogeneity, liquid biopsies are being explored as an alternative to track the dynamics of the disease. Liquid biopsy uses a non-solid tissue sample, such as blood, saliva, urine or cerebrospinal fluid, for the same purposes as traditional biopsy. In addition, samples are investigated for specific biomarkers related to the disease in question, most often circulating tumour cells (CTC), circulation tumour DNA (ctDNA) or exosomes, which can confirm the diagnosis and enable a further follow-up [38]. 
Table 1. Use of EVs in diagnostics of diseases covered by ORL-HNS.

\begin{tabular}{|c|c|}
\hline \multicolumn{2}{|c|}{ Use of EVs in Diagnostics of Diseases Covered by ORL-HNS } \\
\hline Diagnosis based on EV levels & $\begin{array}{l}\text { - Higher levels of salivary EVs predict lymph node } \\
\text { metastasis and higher TNM stage } \\
\text { Specific salivary or plasma EV levels may also prove } \\
\text { helpful for follow-up of HNSCC }\end{array}$ \\
\hline $\begin{array}{l}\text { Diagnosis based on EV } \\
\text { DNA content }\end{array}$ & $\begin{array}{l}\text { - More research is yet to be done on whether EVs isolated } \\
\text { from patients with HNC contain tumour-specific DNA, } \\
\text { especially concerning HPV infection }\end{array}$ \\
\hline $\begin{array}{l}\text { Diagnosis based on EV } \\
\text { RNA content }\end{array}$ & $\begin{array}{l}\text { - Various types of EV miRNAs have been proposed as } \\
\text { potential biomarkers of HNSCC due to their high } \\
\text { specificity and non-invasive sampling } \\
\text { Dysregulation of specific EV miRNAs has been } \\
\text { associated with tissue remodeling in CRS, representing a } \\
\text { potential biomarker of the disease }\end{array}$ \\
\hline $\begin{array}{l}\text { Diagnosis based on the protein } \\
\text { content of extracellular vesicles }\end{array}$ & $\begin{array}{l}\text { Various signal molecules responsible for cancer } \\
\text { regulation and progression seem to have potential as } \\
\text { biomarkers. Upregulation of specific proteins isolated } \\
\text { from EVs is related to nasal mucosa remodelling in CRS }\end{array}$ \\
\hline
\end{tabular}

In recent studies, there has been emphasis on finding potential biomarkers and sampling with non-invasive methods, useful for disease detection and follow up, especially for HNSCC. ORL-HNS—otorhinolaryngology, head and neck surgery; EVs-extracellular vesicles; DNA—-deoxyribonucleic acid; RNA—ribonucleic acid; HNSCC - head and neck squamous cell cancer; HNC — head and neck cancer; HPV-human papillomavirus; miRNAs-micro RNAs; CRS—chronic rhinosinusitis.

\section{Utilisation of EV Levels as Diagnostic Tools}

A comparison of salivary (i.e., derived from saliva) and plasma (i.e., derived from plasma) EVs from patients with oral cancer showed that higher levels of salivary medium/ large EVs were associated with higher levels of plasma medium/large EVs, the presence of lymph node metastasis, and therefore, higher TNM stage (T referring to primary tumour size and site, $\mathrm{N}$ describing (regional) lymph node involvement and $\mathrm{M}$ the presence of distant metastasis) [39]. Additional studies have revealed that salivary EVs in oral cancer are larger, have a more irregular morphology, aggregate more quickly and show a unique infrared signature (i.e., features when analysed with infrared spectroscopy) [40-42]. It remains to be investigated why such morphological changes occur, but they confirm the variations in cancer EVs morphology, which might be a consequence of the total increase in the size of secreted EVs or their aggregation after excretion into body fluids. However, the changes in EV shape, size or structure demonstrate the influence of pathophysiological conditions on modifications at the single-EV level.

A study by Theodoraki et al. (2019) compared the total exosomal protein levels, ratios between tumour-derived exosome (TEX) levels and total exosome levels, and specific immune cell-derived exosomes in patients with HNSCC who remained disease-free at two years after therapy, with those whose disease had recurred in the 2-year followup. In addition, the study evaluated the value of plasma-derived CD3(+) exosomes as an alternative for T cell isolation and CD3(-) TEX as an alternative for tumour biopsies. Patients with locally advanced HNSCC included in the study received a combination therapy with cetuximab, ipilimumab and radiation therapy. In cases that responded to treatment, ultimately, the total exosomal protein levels, TEX levels/total exosome levels ratios, and levels of total CD3+, CD3(-)PD-L1+ and CD3+15s+ (regulatory T cells) exosomes decreased or remained unchanged compared to pre-treatment. In contrast, their levels increased in patients who had experienced a recurrence [43]. These results support the predictive role of exosomes as non-invasively acquired biomarkers in HNSCC. 


\section{Diagnosis Based on DNA Content in EVs}

Little research has been done on EV DNA and its relation to HNC and cancer other than HNC. Some studies suggest that EVs may contain tumour-specific DNA [44,45], and others have additionally shown that EVs are loaded with DNA fragments without any apparent selectivity [10]. In relation to HNC, more research is yet to be done on the topic, and should focus on detecting tumour and human papillomavirus (HPV)-specific DNA, which plays a vital role in HNSCC pathogenesis.

\section{Diagnosis Based on RNA Content in EVs}

More recently, the ability of EVs to transport different types of RNAs, such as messenger RNAs (mRNAs), micro RNAs (miRNAs or miR), long non-coding RNAs (lncRNAs) and circular RNAs (circRNAs), to target cells has become an essential topic of research. So far, the most frequently studied have been miRNAs, which are small, non-coding RNAs that take part in RNA silencing and the post-transcriptional regulation of gene expression. miRNAs are therefore involved in dysregulations, which lead to the development and invasion of many types of cancer. For that reason, EV-derived miRNAs have been studied as potential biomarkers in different types of tumours, including HNSCC [46]. In a recent systemic review, specific exosomal miRNAs from saliva that showed tremendous potential for use as oral and oropharyngeal cancer biomarkers included miR-10b-5p, miR-486-5p, miR-24-3p and miR-200a. All of these are involved in sustaining a favourable microenvironment for tumour growth, whether through modulation of the immune response, tumour cell cycle and proliferation, growth and migration, or invasion and metastasis [47].

Another critical aspect in HNC diagnosis that has been considered in EV profiling is HPV status. HPV+ oropharyngeal cancer shows different molecular, histopathologic and clinical characteristics, affects a different group of patients, and may require less aggressive therapy, with a better outcome than HPV- cancer [48]. An analysis of exosomes produced by HNSCC showed a distinction between HPV+ and HPV- cancer cells. In terms of their immune response, only HPV- cell-derived exosomes suppressed the maturation of dendritic cells and the expression of proteins involved in antigen processing machinery. Further investigations of exosomal miRNA revealed the overexpression of specific miRNAs, such as miR-1972 in HPV- cells and miR-205-5p in HPV+ cells, which may indicate their role in the alteration of antigen processing machinery and tumour immune responses [49].

Another study, by Ramayanti et al. (2019), performed exosomal miRNA sequencing in patients with nasopharyngeal cancer, which is proven to be associated with EBV (EpsteinBarr virus) infection. The study identified a crucial positive correlation between higher circulating EV BART13-3p miRNA levels and nasopharyngeal cancer compared to healthy individuals or those with asymptomatic EBV infection. miR-BART13-3p promotes the migration of tumour cells and metastasis by driving epithelial-mesenchymal transition via the downregulation of the tumour suppressor AB12 [50]. Compared to healthy individuals, its detection appeared to be most specific and selective for nasopharyngeal cancer status in the early and late stages of the disease. This EV biomarker seems to outperform the more classic EBV-DNA load or EBV IgA serology, since it showed higher sensitivity and specificity than the other two more traditional methods [51].

circRNA consists of large, non-coding RNA, which plays a vital role in gene expression regulation by inhibiting miRNAs. Due to its more excellent stability because of its circular structure, it has been thought to have more potential use as a biomarker than linear RNA. The upregulation of specific types of circRNA has been related to laryngeal cancer [52] and the staging of oral cancer [53].

\section{Diagnosis Based on Protein Content in EVs}

Since EVs function as carriers for signal molecules, most of which are proteins, several studies have investigated this type of cargo as a potential biomarker. So far, some of the potential candidates with overexpression in HNSCC-derived EVs are EGFR (epidermal growth factor receptor), PD-L1 (programmed death-ligand 1) and CD44, promoting in- 
creased proliferation, migration and metastatic potential in tumoral cells, as well as a poor prognosis [36]. Another example was the isolation of EV proteins from metastatic oral cancer cells, whereby the molecular chaperones HSP90 (heat shock protein 90), TRAP1(TNF receptor associated protein 1) and HSP105 (heat shock protein 105) were shown to be the most promising metastatic and prognostic biomarkers. They play an essential role in protein-folding, stabilising growth factor receptors and regulating anti-apoptotic pathways, with their increased expression coinciding with a worse prognosis [54].

A study by Qu et al. (2021) has identified a set of EV proteins, dysregulated in EVs, isolated from the plasma of patients with oral tongue squamous cell cancer with or without neck lymph node metastasis. Thus, out of many potential candidates, a lot of them have been established as a potential biomarker for oral tongue squamous cell cancer, some of them (such as platelet factor 4 variant, tubulin beta-4A chain, histone H2B type 2-E, and collagen alpha-1) being informative of nodal status as well [55].

\subsubsection{Sino-Nasal Diseases}

\section{Diagnosis Based on EV miRNA Profile}

A recent study compared healthy individuals, analysing EVs and their miRNA profiles in nasal lavage fluid from patients with chronic rhinosinusitis (CRS). The results showed a statistically significant difference in the expression of specific EV miRNAs (five upregulated and seven downregulated) between patients with CRS and healthy subjects. There was also a statistically significant difference in the expression of miRNAs between patients with CRS with nasal polyposis (CRSwNP) and patients with CRS without nasal polyposis (CRSsNP). The altered miRNA expression allegedly promotes the biosynthesis of specific glycans, which are an essential mechanism for CRS development. In addition, other upregulated or downregulated miRNAs act on specific signalling pathways in the nasal mucosa responsible for tissue remodelling in nasal polyps [29].

A different analysis has suggested the essential role of miR-22-3p isolated from nasal lavage fluid exosomes of patients with CRSwNP, whose overexpression increases vascular permeability by targeting endothelial membrane proteins, aggravating inflammation and tissue oedema [56].

\section{Diagnosis Based on EV Protein Content}

Researchers have suggested that exosomes derived from the nasal mucosa epithelial cells of patients with CRSwNP are partially responsible for creating conditions for abnormal epithelial growth. At the same time, these exosomes contain CRSwNP-specific proteins, which could potentially serve as biomarkers of the persistence or recurrence of nasal polyps after treatment, and facilitate the development of targeted delivery for antagonistic exosomes or anti-exosomal antibodies to neutralise the effects of endogenous exosomes [30].

Several studies have confirmed the altered protein structure and function, or overexpression, of specific proteins in exosomes isolated from nasal mucosa of patients with CRSwNP and CRSsNP. The overexpression of serine protease inhibitors with the downregulation of the fibrinolysis pathway has also been found. This leads to fibrin accumulation in polypoid tissue, a pro-inflammatory environment, and tissue remodelling with fibrosis [57]. Moreover, integrin $\beta 6$ upregulation and the upregulation of the biomarkers involved in endothelial to mesenchymal transformation have been found in basal cells of patients with severe CRSwNP [58]. In exosomes isolated from nasal lavage fluid, airway mucin 5AC upregulation, which promotes tissue remodelling and angiogenesis, was found in patients with nasal polyposis [59].

\subsubsection{Hearing Disorders}

In a study investigating the role of exosomes in middle ear cholesteatoma, keratinocytes and fibroblasts were collected during mastoidectomy and then isolated. The study showed that miRNA-17 from keratinocyte exosomes upregulates fibroblast protein expres- 
sion, promoting the differentiation of osteoclasts and, therefore, bone destruction, and is the essential factor in cholesteatoma pathogenesis [33].

Another study examined the protective role of exosomes in the inner ear. Exosomes isolated from mice utricle, especially supporting cells, exhibited a specific surface-associated protein, HSP70 (70 kilodalton heat shock protein), which interacts with sensory cell surface protein TLR4 (toll-like receptor 4) and further promotes its survival. The exact intracellular signalling pathway of promotion has not been well studied so far. However, since it has been proven that exosomes have an essential role in intracellular communication, protection and promotion of survival in the inner ear, they make a good potential therapeutic deliverer to the site [31].

A new potential use of exosomes has been discovered in terms of their neuroprotective abilities and hearing loss protection in the inner ear. A first in vivo study used human UCMSC (umbilical cord-derived mesenchymal stem cells) EVs to investigate their ability to prevent auditory neuronal damage after exposure to noise trauma. Their use appears to be beneficial, with support of neuronal survival and noise-induced damage repair, presumably by a combination of the EVs' effects on immunomodulatory cytokines, the modification of the intracellular transduction of hair cell function, the morphology of auditory neurons and the release of EV miRNA, which further regulates signalling in target cells, primarily to alter their immune response [32].

Similarly, another study investigated the potential of exosomes isolated from mouse inner ear stem cells and their effect on gentamicin-induced ototoxicity. The study showed that isolated miRNA-182-5p could inhibit pro-apoptotic factors and their signalling pathways, which are deregulated during gentamicin-induced hair cell apoptosis. Again, this discovery provides some new therapeutic options, but has yet to be studied further [60].

\subsection{EV-Based Therapy}

When delivering therapeutics to the site of action, the main obstacles are low accumulation and bioavailability in the target tissue, fast clearance, and the off-target toxicity of the therapeutic. Out of all nanoparticles available, liposomes have been proven to be the most successful delivery vehicles. In terms of their similar properties, EVs also make a probable nano therapy candidate [61]. However, their clinical application remains a challenge. To overcome this challenge, several platforms have been designed to isolate and harvest EVs. These platforms are divided based on their origin: native EVs, EVs from genetically engineered cells, post-modified EVs (drug-loaded or surface modified), and EV-inspired liposomes [11].

\subsubsection{Regenerative Therapy}

To date, a considerable amount of research has been done on the therapeutic use of platelet- and extracellular vesicle-rich plasma (PVRP). PVRP contains a high concentration of platelets and platelet-derived EVs that are primarily known for their regenerative effect. It has been used for years in various surgical fields. In ORL-HNS, PVRP has been chiefly applied for better post-operative wound healing and pain reduction, usually in a gel [1]. The procedures include chronic temporal bone inflammation treatment [62], repair of auricle trauma [63] and eardrum perforation, posterior external ear canal wall reconstruction [64], mastoid reconstruction [65], rhinoplasty [66] in post-surgical nasal packing [67], frontal sinus obliteration [68], anterior skull base CSF leakage [69], aesthetic procedures on the skin of the face and neck [70], cleft lip [71], lesions of the oral mucosa [72], osteoradionecrosis of the mandible [73], pharyngoplasty in obstructive sleep apnea syndrome [74], esophagocutaneous [75] and pharyngocutaneous fistula [76], and suprafacial parotidectomy [1,77].

In contrast to PVRP, EVs have been used in regenerative medicine as isolates in some non-ORL-HNS preclinical settings, e.g., a study by Otahal et al. (2020) investigating the chondroprotective effects of EVs from autologous blood-derived products in the treatment of osteoarthritis. The characterisation of EVs from CPRP (citrate-anticoagulated 
platelet-rich plasma) revealed that EVs from enriched blood products are sufficient to cause changes in chondroprotective and chondrogenic gene expression and the modulation of pro-inflammatory signalling on mRNA and protein levels in osteoarthritis chondrocytes, surpassing total blood products [78].

\subsubsection{Head and Neck Cancer Treatment}

In $\mathrm{HNC}$, EVs have strong potential use as targets of treatment, and also as treatment substances. EVs can be targeted at their synthesis, secretion and internalisation. EVs' unique properties enable them to encapsulate drugs or other bioactive molecules and, therefore, function as drug delivery systems. Moreover, they can directly modulate the immune response in carcinogenesis via the bioactive substances they carry from the mother cell [36].

\section{Treatment via Modulation of EV Synthesis, Secretion and Uptake}

There has been much research on this topic since EVs' biosynthesis and release mechanisms could be modulated, which could be applied to treat various diseases.

It was shown by Zhang et al. (2019) that macrophages stimulated with ODN (CpG oligodeoxynucleotides), a TLR9 (Toll-like receptor) agonist, release EVs carrying ODN and Cdc42. These EVs synergistically stimulate naïve macrophages to propagate an intracellular immune response. This study offers a possible efficient approach to treat various inflammatory diseases based on the modulation of EV secretion and uptake [79].

In investigations of the genetic manipulation of exosome secretion in tumoral cells, the RAB family have been proved to regulate exosome secretion [13]. More specifically, Rab27A/B proteins regulate cancer cell-intrinsic properties while also being involved in exchanging exosomes between different cells within the tumour microenvironment in HNSCC. The genetic deletion of both Rab27A and Rab27B in HNSCC cells reduced the exosome-mediated induction of innervation in vitro and in vivo [80].

A study by Madeo et al. (2018) showed that GW4867, a neutral sphingomyelinase inhibitor, reduces the release of CD9+/CD81+ EVs from HNC, which further reduces the infiltration of nerves into tumoral tissue and therefore the progression of the disease [81]. Targeting EV release or blocking the ability of neurons to spread further in the tumour is thus a good focus in HNSCC treatment. However, it is known that EVs are not involved only in tumorigenesis and disease progression, but also in tumour suppression and immune cell activation [82].

\section{Treatment via Inhibition of EV Internalisation}

There are many different pathways of EV endocytosis, and they usually depend on proteins expressed on the surface of EV and the target cell. It is therefore likely that EVs are taken up by more than one route. There are several substances known to block EV internalisation, but there is still little evidence of the effects of this inhibition. There is also a lack of knowledge of specific steps in this process in relation to HNC. So far, it has been reported that chemotherapeutic cetuximab could have blocking effects on EVs derived from oral tongue cancer, which may be related to surface EGFR [83].

\section{Treatment via Modulation of EV Cargo Components}

With the ability of EVs to transfer biomolecules, they make good drug delivery carrier candidates. There are several known methods of loading EVs with cargo, such as direct incubation with EVs, passive loading by incubation with donor cells, electroporation, sonication, the freeze/thaw method, extrusion, chemical conjugation, and the creation of nanoparticle drug complexes [84]. The goal is to use EVs as carriers and provide better bioavailability and stability to therapeutic molecules [36]. For example, one of the first studies in this field showed that EVs rich with miR-185, derived from mesenchymal stem cells, modulate inflammation, inhibit cell proliferation and angiogenesis, promote 
apoptosis, and thus inhibit the progression of disease in mice with potential oral malignant disorders [85].

\section{Treatment via Immunomodulation Induced by EVs}

The cancer immune cycle includes presenting antigens to antigen presentation cells (APCs) and activating effector T-cells by APCs. Effector T-cells then infiltrate the tumour, where cytotoxic T-cells recognise and kill cancer cells. There are several stimulatory and inhibitory factors included in this pathway, which provide a potential therapeutic target. One of the critical pathways involved in the cancer-immunity cycle, called STING (stimulator of interferon genes), stimulates the interferon genes required to present cancer antigens to T-cells. Recently, a STING agonist combined with the prostaglandin F receptor negative regulator, which activates APCs, has been developed, loaded into EVs, and delivered intratumorally [86]. It was proven that the STING pathway plays an essential role in HPV-related carcinogenesis in HNSCC, which makes it a promising therapeutic for HNC, especially when combined with other already established immunotherapeutics (e.g., cetuximab) [87].

\section{Conclusions}

For quite some time, EVs have been used in spheres of medicine other than ORL-HNS, but these discoveries have enabled the advancement of this trending topic to ORL-HNS. Moreover, research into EVs for theranostic purposes has undoubtedly spread within ORL-HNS areas in the past few years.

To the best of our knowledge, this is the first literature review on the applicability of EVs in ORL-HNS. Research predominates on using EVs in diagnostics and the treatment of HNC. However, new interest has arisen in non-malignant diseases of the ears and sino-nasal area. In terms of diagnostics, most attention has been devoted to non-invasive sampling from body fluids (mainly blood and saliva) and the use of EVs and their specific content as potential biomarkers of HNC. These may be used for making a diagnosis, establishing how far the disease has spread, and following its progression (or regression) before, during and after treatment. The novel, less invasive methods of diagnostics seem to be quite promising, though there is yet more research to be done on whether they offer as accurate a follow-up tool as the current gold standards. Since those methods operate on a molecular level, using particular biomarkers, there are probably more studies to be done on whether these markers are solely for the disease in question, and whether it is possible for them to be an indicator of another condition and be present in healthy tissues as well. While most studies have focused on the role of EV content in relation to the progression of disease, and their potential as biomarkers, some have shed light on their protective abilities, which opens further possibilities for treatment development.

The beneficial effects of EVs in the treatment of ORL-HNS diseases have so far been proven in the use of PVRP, predominantly known for its regenerative effects. When focusing solely on EVs, treatment options become more specific and could, by changing EV creation, function and content, offer a precise cure on a molecular level. The use of EVs in ORL-HNS is a relatively new subject that provides space for much further research. It should concern the most studied types of HNC, which carry the highest disease burden in ORL-HNS and other chronic diseases that can significantly impact the quality of life. These novelties and more specific treatments would offer patients significant health improvements.

Author Contributions: Conceptualization, D.V.; methodology, D.V.; software, M.S.; validation, M.S., S.B. and D.V.; formal analysis, S.B. and D.V; investigation, M.S.; resources, M.S., S.B. and D.V.; data curation, M.S.; writing-original draft preparation, M.S.; writing-review and editing, M.S., S.B. and D.V.; visualization, M.S. and D.V.; supervision, D.V.; project administration, M.S.; funding acquisition, none. All authors have read and agreed to the published version of the manuscript.

Funding: This research received no external funding. 
Conflicts of Interest: The authors declare no conflict of interest. The funders had no role in the design of the study, in the collection, analyses, or interpretation of data; in the writing of the manuscript, or in the decision to publish the results.

\section{References}

1. Vozel, D.; Božič, D.; Jeran, M.; Jan, Z.; Pajnič, M.; Pađen, L.; Uršič, B.; Iglič, A.; Kralj-Iglič, V.; Battelino, S. Treatment with Plateletand Extracellular Vesicle-Rich Plasma in Otorhinolaryngology-a Review and Future Perspectives. In Advances in Biomembranes and Lipid Self-Assembly; Kruze: Oxford, UK, 2021; pp. 119-153. [CrossRef]

2. Théry, C.; Witwer, K.W.; Aikawa, E.; Alcaraz, M.J.; Anderson, J.D.; Andriantsitohaina, R.; Antoniou, A.; Arab, T.; Archer, F.; Atkin-Smith, G.K.; et al. Minimal Information for Studies of Extracellular Vesicles 2018 (MISEV2018): A Position Statement of the International Society for Extracellular Vesicles and Update of the MISEV2014 Guidelines. J. Extracell. Vesicles 2018, 7, 1535750. [CrossRef]

3. Cocozza, F.; Grisard, E.; Martin-Jaular, L.; Mathieu, M.; Théry, C. SnapShot: Extracellular Vesicles. Cell 2020, $182,262-262 . e 1$. [CrossRef]

4. Witwer, K.W.; Théry, C. Extracellular Vesicles or Exosomes? On Primacy, Precision, and Popularity Influencing a Choice of Nomenclature. J. Extracell. Vesicles 2019, 8, 1648167. [CrossRef]

5. van der Pol, E.; Böing, A.N.; Harrison, P.; Sturk, A.; Nieuwland, R. Classification, Functions, and Clinical Relevance of Extracellular Vesicles. Pharmacol. Rev. 2012, 64, 676-705. [CrossRef] [PubMed]

6. van Niel, G.; D'Angelo, G.; Raposo, G. Shedding Light on the Cell Biology of Extracellular Vesicles. Nat. Rev. Mol. Cell Biol. 2018, 19, 213-228. [CrossRef]

7. Kourembanas, S. Exosomes: Vehicles of Intercellular Signaling, Biomarkers, and Vectors of Cell Therapy. Annu. Rev. Physiol. 2015, 77, 13-27. [CrossRef] [PubMed]

8. Thakur, B.K.; Zhang, H.; Becker, A.; Matei, I.; Huang, Y.; Costa-Silva, B.; Zheng, Y.; Hoshino, A.; Brazier, H.; Xiang, J.; et al. Double-Stranded DNA in Exosomes: A Novel Biomarker in Cancer Detection. Cell Res. 2014, 24, 766-769. [CrossRef]

9. Sharma, A.; Johnson, A. Exosome DNA: Critical Regulator of Tumor Immunity and a Diagnostic Biomarker. J. Cell. Physiol. 2020, 235, 1921-1932. [CrossRef]

10. Jeppesen, D.K.; Fenix, A.M.; Franklin, J.L.; Higginbotham, J.N.; Zhang, Q.; Zimmerman, L.J.; Liebler, D.C.; Ping, J.; Liu, Q.; Evans, R.; et al. Reassessment of Exosome Composition. Cell 2019, 177, 428-445.e18. [CrossRef] [PubMed]

11. Herrmann, I.K.; Wood, M.J.A.; Fuhrmann, G. Extracellular Vesicles as a Next-Generation Drug Delivery Platform. Nat. Nanotechnol. 2021, 16, 748-759. [CrossRef] [PubMed]

12. Mulcahy, L.A.; Pink, R.C.; Carter, D.R.F. Routes and Mechanisms of Extracellular Vesicle Uptake. J. Extracell. Vesicles 2014, 3, 24641. [CrossRef]

13. Banks, W.A.; Sharma, P.; Bullock, K.M.; Hansen, K.M.; Ludwig, N.; Whiteside, T.L. Transport of Extracellular Vesicles across the Blood-Brain Barrier: Brain Pharmacokinetics and Effects of Inflammation. Int. J. Mol. Sci. 2020, 21, 4407. [CrossRef] [PubMed]

14. Kolenda, T.; Przybyła, W.; Kapałczyńska, M.; Teresiak, A.; Zajączkowska, M.; Bliźniak, R.; Lamperska, K.M. Tumor Microenvironment-Unknown Niche with Powerful Therapeutic Potential. Rep. Pract. Oncol. Radiother. 2018, $23,143-153$. [CrossRef]

15. Zhang, L.; Yu, D. Exosomes in Cancer Development, Metastasis, and Immunity. Biochim. Et Biophys. Acta Rev. Cancer 2019, 1871, 455-468. [CrossRef] [PubMed]

16. Nazarenko, I.; Rana, S.; Baumann, A.; McAlear, J.; Hellwig, A.; Trendelenburg, M.; Lochnit, G.; Preissner, K.T.; Zoller, M. Cell Surface Tetraspanin Tspan8 Contributes to Molecular Pathways of Exosome-Induced Endothelial Cell Activation. Cancer Res. 2010, 70, 1668-1678. [CrossRef] [PubMed]

17. Fidler, I.J. The Pathogenesis of Cancer Metastasis: The "seed and Soil" Hypothesis Revisited. Nat. Rev. Cancer 2003, 3, 453-458. [CrossRef]

18. Ono, K.; Sogawa, C.; Kawai, H.; Tran, M.T.; Taha, E.A.; Lu, Y.; Oo, M.W.; Okusha, Y.; Okamura, H.; Ibaragi, S.; et al. Triple Knockdown of CDC37, HSP90-alpha and HSP90-beta Diminishes Extracellular Vesicles-driven Malignancy Events and Macrophage M2 Polarization in Oral Cancer. J. Extracell. Vesicles 2020, 9, 1769373. [CrossRef]

19. Whiteside, T.L. Head and Neck Carcinoma Immunotherapy: Facts and Hopes. Clin. Cancer Res. 2018, 24, 6-13. [CrossRef]

20. Razzo, B.M.; Ludwig, N.; Hong, C.-S.; Sharma, P.; Fabian, K.P.; Fecek, R.J.; Storkus, W.J.; Whiteside, T.L. Tumor-Derived Exosomes Promote Carcinogenesis of Murine Oral Squamous Cell Carcinoma. Carcinogenesis 2020, 41, 625-633. [CrossRef]

21. Gao, Q.; Liu, H.-T.; Xu, Y.-Q.; Zhang, L.; Liu, Y.-R.; Ren, Q.; Sheng, J.-P.; Zhang, Z.-X. Serum-Derived Exosomes Promote CD8+ T Cells to Overexpress PD-1, Affecting the Prognosis of Hypopharyngeal Carcinoma. Cancer Cell Int. 2021, 21, 584. [CrossRef]

22. Ludwig, S.; Floros, T.; Theodoraki, M.-N.; Hong, C.-S.; Jackson, E.K.; Lang, S.; Whiteside, T.L. Suppression of Lymphocyte Functions by Plasma Exosomes Correlates with Disease Activity in Patients with Head and Neck Cancer. Clin. Cancer Res. Off. J. Am. Assoc. Cancer Res. 2017, 23, 4843-4854. [CrossRef] [PubMed]

23. Lötvall, J.; Hill, A.F.; Hochberg, F.; Buzás, E.I.; Di Vizio, D.; Gardiner, C.; Gho, Y.S.; Kurochkin, I.V.; Mathivanan, S.; Quesenberry, P.; et al. Minimal experimental requirements for definition of extracellular vesicles and their functions: A position statement from the International Society for Extracellular Vesicles. J. Extracell. Vesicles 2014, 3, 26913. [CrossRef] 
24. Liangsupree, T.; Multia, E.; Riekkola, M.L. Modern Isolation and Separation Techniques for Extracellular Vesicles. J. Chromatogr. A 2021, 1636, 461773. [CrossRef]

25. Doyle, L.M.; Wang, M.Z. Overview of Extracellular Vesicles, Their Origin, Composition, Purpose, and Methods for Exosome Isolation and Analysis. Cells 2019, 8, 727. [CrossRef]

26. Tschuschke, M.; Kocherova, I.; Bryja, A.; Mozdziak, P.; Angelova Volponi, A.; Janowicz, K.; Sibiak, R.; Piotrowska-Kempisty, H.; Iżycki, D.; Bukowska, D.; et al. Inclusion Biogenesis, Methods of Isolation and Clinical Application of Human Cellular Exosomes. J. Clin. Med. 2020, 9, 436. [CrossRef] [PubMed]

27. Royo, F.; Théry, C.; Falcón-Pérez, J.M.; Nieuwland, R.; Witwer, K.W. Methods for Separation and Characterization of Extracellular Vesicles: Results of a Worldwide Survey Performed by the ISEV Rigor and Standardization Subcommittee. Cells 2020, 9, 1955. [CrossRef] [PubMed]

28. Cao, J.; Zhang, M.; Xie, F.; Lou, J.; Zhou, X.; Zhang, L.; Fang, M.; Zhou, F. Exosomes in Head and Neck Cancer: Roles, Mechanisms and Applications. Cancer Lett. 2020, 494, 7-16. [CrossRef] [PubMed]

29. Cha, S.; Seo, E.-H.; Lee, S.H.; Kim, K.S.; Oh, C.-S.; Moon, J.-S.; Kim, J.K. MicroRNA Expression in Extracellular Vesicles from Nasal Lavage Fluid in Chronic Rhinosinusitis. Biomedicines 2021, 9, 471. [CrossRef]

30. Zhou, M.; Tan, K.S.; Guan, W.; Jiang, L.; Deng, J.; Gao, W.; Lee, Y.M.; Xu, Z.; Luo, X.; Liu, C.; et al. Proteomics Profiling of Epithelium-Derived Exosomes from Nasal Polyps Revealed Signaling Functions Affecting Cellular Proliferation. Respir. Med. 2020, 162, 105871. [CrossRef]

31. Breglio, A.M.; May, L.A.; Barzik, M.; Welsh, N.C.; Francis, S.P.; Costain, T.Q.; Wang, L.; Anderson, D.E.; Petralia, R.S.; Wang, Y.-X.; et al. Exosomes Mediate Sensory Hair Cell Protection in the Inner Ear. J. Clin. Investig. 2020, 130, 2657-2672. [CrossRef]

32. Warnecke, A.; Harre, J.; Staecker, H.; Prenzler, N.; Strunk, D.; Couillard-Despres, S.; Romanelli, P.; Hollerweger, J.; Lassacher, T.; Auer, D.; et al. Extracellular Vesicles from Human Multipotent Stromal Cells Protect against Hearing Loss after Noise Trauma in Vivo. Clin. Transl. Med. 2020, 10, e262. [CrossRef]

33. Gong, N.Y.; Zhu, W.; Xu, R.; Teng, Z.; Deng, C.; Zhou, H.; Xia, M.; Zhao, M. Keratinocytes-Derived Exosomal MiRNA Regulates Osteoclast Differentiation in Middle Ear Cholesteatoma. Biochem. Biophys. Res. Commun. 2020, 525, 341-347. [CrossRef] [PubMed]

34. Zhang, Y.; Shi, S.; Xu, Q.; Zhang, Q.; Shanti, R.M.; Le, A.D. SIS-ECM Laden with GMSC-Derived Exosomes Promote Taste Bud Regeneration. J. Dent. Res. 2019, 98, 225-233. [CrossRef] [PubMed]

35. Gillison, M.L.; D’Souza, G.; Westra, W.; Sugar, E.; Xiao, W.; Begum, S.; Viscidi, R. Distinct Risk Factor Profiles for Human Papillomavirus Type 16-Positive and Human Papillomavirus Type 16-Negative Head and Neck Cancers. JNCI J. Natl. Cancer Inst. 2008, 100, 407-420. [CrossRef]

36. Qu, X.; Li, J.-W.; Chan, J.; Meehan, K. Extracellular Vesicles in Head and Neck Cancer: A Potential New Trend in Diagnosis, Prognosis, and Treatment. Int. J. Mol. Sci. 2020, 21, 8260. [CrossRef] [PubMed]

37. Hoshino, A.; Kim, H.S.; Bojmar, L.; Gyan, K.E.; Cioffi, M.; Hernandez, J.; Zambirinis, C.P.; Rodrigues, G.; Molina, H.; Heissel, S.; et al. Extracellular Vesicle and Particle Biomarkers Define Multiple Human Cancers. Cell 2020, 182, 1044-1061.e18. [CrossRef] [PubMed]

38. Burklund, A.; Tadimety, A.; Nie, Y.; Hao, N.; Zhang, J.X.J. Advances in Diagnostic Microfluidics. Adv. Clin. Chem. 2020, 95, 1-72. [CrossRef]

39. Zhong, W.; Ren, J.; Xiong, X.; Man, Q.; Zhang, W.; Gao, L.; Li, C.; Liu, B.; Sun, Z.; Jia, J.; et al. Increased Salivary Microvesicles Are Associated with the Prognosis of Patients with Oral Squamous Cell Carcinoma. J. Cell. Mol. Med. 2019, 23, 4054-4062. [CrossRef]

40. Sharma, S.; Gillespie, B.M.; Palanisamy, V.; Gimzewski, J.K. Quantitative Nanostructural and Single-Molecule Force Spectroscopy Biomolecular Analysis of Human-Saliva-Derived Exosomes. Langmuir 2011, 27, 14394-14400. [CrossRef]

41. Zlotogorski-Hurvitz, A.; Dekel, B.Z.; Malonek, D.; Yahalom, R.; Vered, M. FTIR-Based Spectrum of Salivary Exosomes Coupled with Computational-Aided Discriminating Analysis in the Diagnosis of Oral Cancer. J. Cancer Res. Clin. Oncol. 2019, 145, 685-694. [CrossRef] [PubMed]

42. Zlotogorski-Hurvitz, A.; Dayan, D.; Chaushu, G.; Salo, T.; Vered, M. Morphological and Molecular Features of Oral Fluid-Derived Exosomes: Oral Cancer Patients versus Healthy Individuals. J. Cancer Res. Clin. Oncol. 2016, 142, 101-110. [CrossRef]

43. Theodoraki, M.-N.; Yerneni, S.; Gooding, W.E.; Ohr, J.; Clump, D.A.; Bauman, J.E.; Ferris, R.L.; Whiteside, T.L. Circulating Exosomes Measure Responses to Therapy in Head and Neck Cancer Patients Treated with Cetuximab, Ipilimumab, and IMRT. OncoImmunology 2019, 8, e1593805. [CrossRef]

44. Vagner, T.; Spinelli, C.; Minciacchi, V.R.; Balaj, L.; Zandian, M.; Conley, A.; Zijlstra, A.; Freeman, M.R.; Demichelis, F.; De, S.; et al. Large Extracellular Vesicles Carry Most of the Tumour DNA Circulating in Prostate Cancer Patient Plasma. J. Extracell. Vesicles 2018, 7, 1505403. [CrossRef]

45. Kahlert, C.; Melo, S.A.; Protopopov, A.; Tang, J.; Seth, S.; Koch, M.; Zhang, J.; Weitz, J.; Chin, L.; Futreal, A.; et al. Identification of Double-Stranded Genomic DNA Spanning All Chromosomes with Mutated KRAS and P53 DNA in the Serum Exosomes of Patients with Pancreatic Cancer. J. Biol. Chem. 2014, 289, 3869-3875. [CrossRef]

46. Min, L.; Zhu, S.; Chen, L.; Liu, X.; Wei, R.; Zhao, L.; Yang, Y.; Zhang, Z.; Kong, G.; Li, P.; et al. Evaluation of Circulating Small Extracellular Vesicles Derived MiRNAs as Biomarkers of Early Colon Cancer: A Comparison with Plasma Total MiRNAs. J. Extracell. Vesicles 2019, 8, 1643670. [CrossRef] [PubMed]

47. Faur, C.I.; Rotaru, H.; Osan, C.; Jurj, A.; Roman, R.C.; Moldovan, M.; Chirila, M.; Hedesiu, M. Salivary Exosomal MicroRNAs as Biomarkers for Head and Neck Cancer Detection-a Literature Review. Maxillofac. Plast. Reconstr. Surg. 2021, 43, 19. [CrossRef] 
48. Leemans, C.R.; Braakhuis, B.J.M.; Brakenhoff, R.H. The Molecular Biology of Head and Neck Cancer. Nat. Rev. Cancer 2011, 11, 9-22. [CrossRef] [PubMed]

49. Ludwig, S.; Sharma, P.; Wise, P.; Sposto, R.; Hollingshead, D.; Lamb, J.; Lang, S.; Fabbri, M.; Whiteside, T.L. MRNA and MiRNA Profiles of Exosomes from Cultured Tumor Cells Reveal Biomarkers Specific for HPV16-Positive and HPV16-Negative Head and Neck Cancer. Int. J. Mol. Sci. 2020, 21, 8570. [CrossRef] [PubMed]

50. Huang, J.; Qin, Y.; Yang, C.; Wan, C.; Dai, X.; Sun, Y.; Meng, J.; Lu, Y.; Li, Y.; Zhang, Z.; et al. Downregulation of ABI2 Expression by EBV-MiR-BART13-3p Induces Epithelial-Mesenchymal Transition of Nasopharyngeal Carcinoma Cells through Upregulation of c-JUN/SLUG Signaling. Aging 2020, 12, 340-358. [CrossRef]

51. Ramayanti, O.; Verkuijlen, S.A.W.M.; Novianti, P.; Scheepbouwer, C.; Misovic, B.; Koppers-Lalic, D.; Weering, J.; Beckers, L.; Adham, M.; Martorelli, D.; et al. Vesicle-bound EBV-BART13-3p MiRNA in Circulation Distinguishes Nasopharyngeal from Other Head and Neck Cancer and Asymptomatic EBV-infections. Int. J. Cancer 2019, 144, 2555-2566. [CrossRef]

52. Tian, L.; Cao, J.; Jiao, H.; Zhang, J.; Ren, X.; Liu, X.; Liu, M.; Sun, Y. CircRASSF2 Promotes Laryngeal Squamous Cell Carcinoma Progression by Regulating the MiR-302b-3p/IGF-1R Axis. Clin. Sci. 2019, 133, 1053-1066. [CrossRef]

53. Luo, Y.; Liu, F.; Guo, J.; Gui, R. Upregulation of Circ_0000199 in Circulating Exosomes Is Associated with Survival Outcome in OSCC. Sci. Rep. 2020, 10, 13739. [CrossRef]

54. Ono, K.; Eguchi, T.; Sogawa, C.; Calderwood, S.K.; Futagawa, J.; Kasai, T.; Seno, M.; Okamoto, K.; Sasaki, A.; Kozaki, K. HSP-enriched Properties of Extracellular Vesicles Involve Survival of Metastatic Oral Cancer Cells. J. Cell. Biochem. 2018, 119, 7350-7362. [CrossRef] [PubMed]

55. Qu, X.; Leung, T.C.N.; Ngai, S.-M.; Tsai, S.-N.; Thakur, A.; Li, W.-K.; Lee, Y.; Leung, L.; Ng, T.-H.; Yam, J.; et al. Proteomic Analysis of Circulating Extracellular Vesicles Identifies Potential Biomarkers for Lymph Node Metastasis in Oral Tongue Squamous Cell Carcinoma. Cells 2021, 10, 2179. [CrossRef]

56. Zhang, W.; Zhang, T.; Yan, Y.; Zhang, J.; Zhou, Y.; Pei, Y.; Yao, L.; You, B.; Chen, J. Exosomal MiR-22-3p Derived from Chronic Rhinosinusitis with Nasal Polyps Regulates Vascular Permeability by Targeting VE-Cadherin. BioMed Res. Int. 2020, 2020, 1237678. [CrossRef]

57. Mueller, S.K.; Nocera, A.L.; Dillon, S.T.; Libermann, T.A.; Wendler, O.; Bleier, B.S. Tissue and Exosomal Serine Protease Inhibitors Are Significantly Overexpressed in Chronic Rhinosinusitis With Nasal Polyps. Am. J. Rhinol. Allergy 2019, 33, 359-368. [CrossRef]

58. Takahashi, T.; Kato, A.; Suh, L.A.; Carter, R.G.; Stevens, W.W.; Price, C.P.E.; Norton, J.E.; Weibman, A.R.; Harris, K.E.; Peters, A.T.; et al. Integrin B6 Microparticles in Nasal Lavage Fluids; Potential New Biomarkers for Basal Cell Activation in Chronic Rhinosinusitis. Allergy 2020, 75, 3261-3264. [CrossRef]

59. Wang, L.-F.; Lee, C.-H.; Liang, S.-S.; Hung, C.-C.; Wu, Y.-R.; Chien, C.-Y.; Lee, C.-H.; Chen, J.Y.-F. Mucin 5AC Is Significantly Upregulated in Exosomes from the Nasal Lavage Fluid and May Promote the Expression of COX-2, VEGF and MMP-9: An Implication in Nasal Polyp Pathogenesis. Rhinol. J. 2021, 59, 328-336. [CrossRef]

60. Lai, R.; Cai, C.; Wu, W.; Hu, P.; Wang, Q. Exosomes Derived from Mouse Inner Ear Stem Cells Attenuate Gentamicin-induced Ototoxicity in Vitro through the MiR-182-5p/FOXO3 Axis. J. Tissue Eng. Regen. Med. 2020, 14, 1149-1156. [CrossRef] [PubMed]

61. de Castilla, P.E.M.; Tong, L.; Huang, C.; Sofias, A.M.; Pastorin, G.; Chen, X.; Storm, G.; Schiffelers, R.M.; Wang, J.-W. Extracellular Vesicles as a Drug Delivery System: A Systematic Review of Preclinical Studies. Adv. Drug Deliv. Rev. 2021, $175,113801$. [CrossRef] [PubMed]

62. Vozel, D.; Božič, D.; Jeran, M.; Jan, Z.; Pajnič, M.; Pađen, L.; Steiner, N.; Kralj-Iglič, V.; Battelino, S. Autologous Plateletand Extracellular Vesicle-Rich Plasma Is an Effective Treatment Modality for Chronic Postoperative Temporal Bone Cavity Inflammation: Randomized Controlled Clinical Trial. Front. Bioeng. Biotechnol. 2021, 9, 677541. [CrossRef]

63. Lee, S.K.; Lim, Y.M.; Lew, D.H.; Song, S.Y. Salvage of Unilateral Complete Ear Amputation with Continuous Local Hyperbaric Oxygen, Platelet-Rich Plasma and Polydeoxyribonucleotide without Micro-Revascularization. Arch. Plast. Surg. 2017, 44, 554-558. [CrossRef] [PubMed]

64. Elbary, M.; Nasr, W.; Sorour, S. Platelet-Rich Plasma in Reconstruction of Posterior Meatal Wall after Canal Wall Down Mastoidectomy. Int. Arch. Otorhinolaryngol. 2018, 22, 103-107. [CrossRef] [PubMed]

65. Askar, S.M.; Saber, I.M.; Omar, M. Mastoid Reconstruction With Platelet-Rich Plasma and Bone Pate After Canal Wall Down Mastoidectomy: A Preliminary Report. Ear Nose Throat J. 2021, 100, 485-489. [CrossRef] [PubMed]

66. Gode, S.; Ozturk, A.; Kısmalı, E.; Berber, V.; Turhal, G. The Effect of Platelet-Rich Fibrin on Nasal Skin Thickness in Rhinoplasty. Facial Plast. Surg. 2019, 35, 400-403. [CrossRef]

67. Kuzucu, I.; Beriat, G.K.; Ezerarslan, H.; Ozdemir, S.; Kocaturk, S. Effects of the Autologous Platelet-Rich Plasma in Nasal Pack on Postoperative Quality of Life. J. Craniofacial Surg. 2017, 28, e299-e302. [CrossRef]

68. Mendonça-Caridad, J.J.; Juiz-Lopez, P.; Rubio-Rodriguez, J.P. Frontal Sinus Obliteration and Craniofacial Reconstruction with Platelet Rich Plasma in a Patient with Fibrous Dysplasia. Int. J. Oral Maxillofac. Surg. 2006, 35, 88-91. [CrossRef]

69. Khafagy, Y.W.; Elfattah, A.M.A.; Moneir, W.; Salem, E.H. Leukocyte- and Platelet-Rich Fibrin: A New Graft Material in Endoscopic Repair of Spontaneous CSF Leaks. Eur. Arch. Oto-Rhino-Laryngol. 2018, 275, 2245-2252. [CrossRef]

70. Maisel-Campbell, A.L.; Ismail, A.; Reynolds, K.A.; Poon, E.; Serrano, L.; Grushchak, S.; Farid, C.; West, D.P.; Alam, M. A Systematic Review of the Safety and Effectiveness of Platelet-Rich Plasma (PRP) for Skin Aging. Arch. Dermatol. Res. 2020, 312, 301-315. [CrossRef] 
71. Refahee, S.M.; Aboulhassan, M.A.; Aziz, O.A.; Emara, D.; Seif El Dein, H.M.; Moussa, B.G.; Abu Sneineh, M. Is PRP Effective in Reducing the Scar Width of Primary Cleft Lip Repair? A Randomized Controlled Clinical Study. Cleft Palate-Craniofacial J. 2020, 57, 581-588. [CrossRef]

72. Mahajan, M.; Gupta, M.K.; Bande, C.; Meshram, V. Comparative Evaluation of Healing Pattern After Surgical Excision of Oral Mucosal Lesions by Using Platelet-Rich Fibrin (PRF) Membrane and Collagen Membrane as Grafting Materials-A Randomized Clinical Trial. J. Oral Maxillofac. Surg. 2018, 76, 1469.e1-1469.e9. [CrossRef]

73. Scala, M.; Gipponi, M.; Mereu, P.; Strada, P.; Corvò, R.; Muraglia, A.; Massa, M.; Bertoglio, S.; Santi, P.; Cafiero, F. Regeneration of Mandibular Osteoradionecrosis Defect with Platelet Rich Plasma Gel. In Vivo 2010, 24, 889-893.

74. Elkahwagi, M.; Elokda, M.; Elghannam, D.; Elsobki, A. Role of Autologous Platelet-Rich Fibrin in Relocation Pharyngoplasty for Obstructive Sleep Apnoea. Int. J. Oral Maxillofac. Surg. 2020, 49, 200-206. [CrossRef]

75. Joudi, M.; Hamidi Alamdari, D.; Hyradfar, M.; Rahimi, H.R.; Saremi, E.; Fathi, M.; Shojaeian, R.; Koliakos, G. Lateral Traumatic Esophago-Cutaneous Fistula in a Child; Platelet-Rich Fibrin Glue Challenge. Iran. Red Crescent Med J. 2013, 15, 256-259. [CrossRef] [PubMed]

76. Eryılmaz, A.; Demirci, B.; Gunel, C.; Kacar Doger, F.; Yukselen, O.; Kurt Omurlu, I.; Basal, Y.; Agdas, F.; Basak, S. Can Tissue Adhesives and Platelet-Rich Plasma Prevent Pharyngocutaneous Fistula Formation? Auris Nasus Larynx 2016, 43, 62-67. [CrossRef] [PubMed]

77. Ricci, E.; Riva, G.; Dagna, F.; Cavalot, A.L. The Use of Platelet-Rich Plasma Gel in Superficial Parotidectomy. Acta Otorhinolaryngol. Ital. 2019, 39, 363-366. [CrossRef] [PubMed]

78. Otahal, A.; Kramer, K.; Kuten-Pella, O.; Weiss, R.; Stotter, C.; Lacza, Z.; Weber, V.; Nehrer, S.; de Luna, A. Characterization and Chondroprotective Effects of Extracellular Vesicles From Plasma- and Serum-Based Autologous Blood-Derived Products for Osteoarthritis Therapy. Front. Bioeng. Biotechnol. 2020, 8, 584050. [CrossRef]

79. Zhang, Y.; Jin, X.; Liang, J.; Guo, Y.; Sun, G.; Zeng, X.; Yin, H. Extracellular Vesicles Derived from ODN-Stimulated Macrophages Transfer and Activate Cdc42 in Recipient Cells and Thereby Increase Cellular Permissiveness to EV Uptake. Sci. Adv. 2019, 5, eaav1564. [CrossRef] [PubMed]

80. McAndrews, K.M.; Kalluri, R. Mechanisms Associated with Biogenesis of Exosomes in Cancer. Mol. Cancer 2019, 18, 52. [CrossRef] [PubMed]

81. Madeo, M.; Colbert, P.L.; Vermeer, D.W.; Lucido, C.T.; Cain, J.T.; Vichaya, E.G.; Grossberg, A.J.; Muirhead, D.; Rickel, A.P.; Hong, Z.; et al. Cancer Exosomes Induce Tumor Innervation. Nat. Commun. 2018, 9, 4284. [CrossRef]

82. Whiteside, T.L. Exosomes and Tumor-Mediated Immune Suppression. J. Clin. Investig. 2016, 126, 1216-1223. [CrossRef] [PubMed]

83. Licitra, L.; Mesia, R.; Rivera, F.; Remenár, É.; Hitt, R.; Erfán, J.; Rottey, S.; Kawecki, A.; Zabolotnyy, D.; Benasso, M.; et al. Evaluation of EGFR Gene Copy Number as a Predictive Biomarker for the Efficacy of Cetuximab in Combination with Chemotherapy in the First-Line Treatment of Recurrent and/or Metastatic Squamous Cell Carcinoma of the Head and Neck: EXTREME Study. Ann. Oncol. Off. J. Eur. Soc. Med. Oncol. 2011, 22, 1078-1087. [CrossRef] [PubMed]

84. Elsharkasy, O.M.; Nordin, J.Z.; Hagey, D.W.; de Jong, O.G.; Schiffelers, R.M.; Andaloussi, S.E.; Vader, P. Extracellular Vesicles as Drug Delivery Systems: Why and How? Adv. Drug Deliv. Rev. 2020, 159, 332-343. [CrossRef] [PubMed]

85. Wang, L.; Yin, P.; Wang, J.; Wang, Y.; Sun, Z.; Zhou, Y.; Guan, X. Delivery of Mesenchymal Stem Cells-Derived Extracellular Vesicles with Enriched MiR-185 Inhibits Progression of OPMD. Artif. Cells Nanomed. Biotechnol. 2019, 47, 2481-2491. [CrossRef]

86. Jang, S.C.; Moniz, R.J.; Sia, C.L.; Harrison, R.A.; Houde, D.; Ross, N.; Xu, K.; Lewis, N.; Bourdeau, R.; McCoy, C.; et al. Abstract 944: ExoSTING: An Engineered Exosome Therapeutic That Selectively Delivers STING Agonist to the Tumor Resident AntigenPresenting Cells Resulting in Improved Tumor Antigen-Specific Adaptive Immune Response. In Proceedings of the AACR Annual Meeting 2019, Atlanta, GA, USA, 29 March-3 April 2019; American Association for Cancer Research: Philadelphia, PA, USA, 2019. [CrossRef]

87. Lu, S.; Concha-Benavente, F.; Shayan, G.; Srivastava, R.M.; Gibson, S.P.; Wang, L.; Gooding, W.E.; Ferris, R.L. STING Activation Enhances Cetuximab-Mediated NK Cell Activation and DC Maturation and Correlates with HPV+ Status in Head and Neck Cancer. Oral Oncol. 2018, 78, 186-193. [CrossRef] [PubMed] 